\title{
Lung cancer among glass fibre production workers: a case-control study
}

\author{
M J GARDNER, C MAGNANI,* B PANNETT, A C FLETCHER, P D WINTER \\ From the Medical Research Council Environmental Epidemiology Unit (University of Southampton), \\ Southampton General Hospital, Southampton SO9 4XY,UK
}

\begin{abstract}
A cohort study among 4734 employees at an English glass fibre plant previously reported no excess of lung cancer mortality either overall or when examined in broad occupational groups. To investigate occupation in more detail, and to test the hypothesis that processes producing or using finer (respirable) fibres may be related to a higher risk of lung cancer, a nested case-control study has now been carried out. Included are 73 cases of lung cancer and 506 matched controls, for whom jobs held and processes worked on have been blindly recoded in more detail than for the cohort study. Workers known to have been employed on processes containing respirable fibres had a relative risk of lung cancer of $1.2(95 \%$ confidence interval $0.7-2.0)$ compared with other workers. There was no evidence of a relationship of lung cancer to fibre diameter, duration of exposure, or time since first exposure. The results by broad occupational group were similar to those of the cohort study, and although some of the many detailed occupational categories examined had significantly raised relative risks, these did not appear to be related to exposure to respirable glass fibre. Although the study has not indicated a differential risk of lung cancer among workers exposed to finer diameter glass fibres, the exposure levels were low and the number of cases small.
\end{abstract}

Mortality among the workforce of an English glass fibre factory has been studied to the end of 1984 as part of the collaborative European investigation of workers in the manmade mineral fibre production industry. ${ }^{12}$ Among the workers in all glass wool plants of the European study there were 93 deaths from lung cancer observed compared with 91 expected (standardised mortality ratio 103) on the basis of national death rates adjusted for local mortality. The largest contribution to the European glass fibre workforce came from the English factory, and data were presented ${ }^{1}$ to indicate that these workers were locally based and hence, although there was an excess of lung cancer compared with death rates in England and Wales, such a national comparison was inappropriate. Among the factory workforce, 76 deaths from lung cancer were reported compared with 72 expected at local rates (and 59 expected at national rates). There was no consistent relation of lung cancer mortality with either duration of employment or period since entry into employment. Mortality from lung cancer was higher than expected

Accepted 7 September 1987

*Current address: Servizio di Epidemiologia dei Tumori, Dipartimento di Oncologia, V Santena 7, 10126 Turin, Italy. among those working in fibre production, in secondary processes using glass wool as a raw material, and in maintenance but did not reach statistical significance for any occupational group.

In the analysis of the whole workforce just described the occupational history was considered only in broad categories. It was decided, therefore, to use a nested case-control design to investigate risks of lung cancer by detailed job category, and to test the hypothesis that working on processes producing or using finer fibres may be related to a higher risk of lung cancer. Such a case-control study has the advantage that it involves detailed job coding for only a fraction of the total workforce but does not substantially reduce the statistical power.

\section{Methods}

PRODUCTION PROCESSES AT THE FACTORY

The factory has been manufacturing glass fibre of varying nominal diameters for a range of products since 1943.

Superfine fibre was manufactured for two periods between 1949 and 1968 and the product used in aircraft insulation. A flame attenuation process ran 
from 1949 to 1957 producing fibres of nominal diameter 1-3 microns, and a rotary TEL (derived from Laboratoire Experimental Thermique) process from 1962 to 1968 produced fibres of nominal diameter $2-5$ microns.

From 1945 to 1962 the Owens steam blowing process was used to produce glass wool fibre of nominal diameter 12-15 microns. By 1962 all the main wool lines had been converted to the rotary TEL process, which was introduced in 1959 and produced fibre of nominal diameter 6-7 microns. In both processes the end use for the wool was as insulation in the form of rolls and slabs. Pipe insulation was produced from the main wool lines by secondary processes of rolling (1949-57) and pressing (1957-82). Other products manufactured at various times from the main wool lines have been moulded products (1962-85), dense slabs (1964-81), mattresses and quilts (1946-78), acoustic tiles (1958-62), navy boards (1950 to present), and shredded wool for wall insulation (1978 to present).

A slightly different steam blowing process was used in the production of staple fibres. Staple tissue, with a nominal fibre diameter of 11-13 microns, was made from 1948 to 1978 for use in the manufacture of air filters, battery separators, boards, and reinforced laminates. Staple fibres, with a nominal diameter of 810 microns, were produced from 1944 to 1959 and, after a doubling and twisting stage, formed into staple slivers and yarns.

A mechanical drawing process was used from 1954 to 1970 for the production of continuous filament fibres having a nominal diameter of 9-13 microns. These continuous filaments were used in the manufacture of yarns, chopped strand mats, rovings, and coated yarns.

Fibres with larger nominal diameters, 20 to 25 microns and 1000 microns, were manufactured from 1953 to 1980 by a steam blowing process and used in the production of air filter units.

Since the plant started operation in 1943 the main products have all been treated with bitumen or resin binder with or without the addition of oil. In superfine fibre production, and in a small proportion of glass wool production, resin alone was added. The addition of oil, and to much lesser degree bitumen or resin, has a dust suppressant effect. ${ }^{3}$

Of the above products, superfine fibre and glass wools produced by the Owens and TEL processes include fibres of respirable size (defined as diameter < 3 microns, length $>5$ microns, and aspect ratio greater than $3: 1)$. Staple products contain virtually no respirable fibres, mainly because the manufacturing process is designed to produce coarse long fibres. Being bonded, all staple products exhibit a low tendency to release respirable fibres.
The only available measures of airborne glass fibre concentrations on the plant were obtained in 1977 as part of the collaborative European study already mentioned. Mean respirable fibre levels by work area were reported to range from $0.01 \mathrm{f} / \mathrm{ml}$ in preproduction areas to $0.16 \mathrm{f} / \mathrm{ml}$ in the dustier secondary processes, with a mean level of $0.05 \mathrm{f} / \mathrm{ml}$ in the production areas. ${ }^{4}$ In the glass wool production area mean fibre concentrations were measured at $0.06 \mathrm{f} / \mathrm{ml}$, compared with $0.01 \mathrm{f} / \mathrm{ml}$ in the staple tissue production area $(\mathrm{J}$ Cherrie, personal communication). No environmental exposure data are available for superfine fibre production in this factory, but measurements taken elsewhere in the glass fibre industry gave relatively high levels (more than one $\mathrm{f} / \mathrm{ml}$ ) for fine (less than two microns nominal diameter) glass fibre production and use compared with coarser fibre production. ${ }^{4}$

CLASSIFICATION OF CASES, CONTROLS, JOBS, AND EXPOSURE

The workforce investigated, described in detail by Gardner et al, ${ }^{1}$ includes 3548 men and 1186 women employed between April 1946 and December 1978 for at least one year. They were followed up through the National Health Service Central Register to 31 December 1984 to ascertain vital status and cause of death where appropriate. Excluding office workers, 73 deaths from lung cancer (66 men, seven women) were identified. Each case was matched for sex and year of birth (to within 2.5 years) with up to eight controls. These were chosen randomly from all eligible workers who were alive and had been employed for at least one year at the time of death of the corresponding case. Although eight controls were not available for all cases, on average each case was matched with 6.9 controls. Table 1 shows the distribution of controls per case.

Information collected from the factory records at the outset of the cohort study included dates of starting and leaving, department, clock number, and title for all jobs held. About 600 job descriptions were coded by two of the authors (BP and CM) with the help of technical staff from the factory. Each job description was assigned a specific code for the job

Table 1 Number of deaths from lung cancer in the casecontrol study showing the number of matched controls

\begin{tabular}{lcc}
\hline $\begin{array}{l}\text { No of matched controls } \\
\text { per case }\end{array}$ & No of cases & No of controls \\
\hline 8 & 47 & 376 \\
7 & 5 & 35 \\
6 & 5 & 30 \\
5 & 7 & 35 \\
4 & 3 & 12 \\
3 & 6 & 18 \\
Total & 73 & 506 \\
\hline
\end{tabular}


category and the type of fibre produced or handled, making more use of job titles, clock numbers, and department names than in the cohort analysis. These codes were also aggregated into the same combined occupational groups as were used in the cohort analysis with two exceptions through the definition of extra groups: research and development, and warehousing. Research and development workers were previously within the maintenance combined occupational group. Unfortunately, hygiene measurements were not available for the research and development group alone, and so in the ranking of occupational groups by fibre exposure (see table 3b) they have been placed adjacent to the maintenance group. Work in the warehouses entailed some cutting and sawing of manmade mineral fibre products, as in the secondary processes category. In the original analysis warehouse workers had been categorised into either secondary processes or general works categories. A few jobs previously in the general works category in the cohort study are now coded as unexposed.

Potential exposure to asbestos in the factory, based on job title, was also coded. Job categories with some potential for asbestos exposure were those located in the melting tank area of production, maintenance workers in research and development, and maintenance mechanics, electricians, engineers, and plumbers.

The coding scheme was reviewed by J Cherrie, at the Institute of Occupational Medicine, who was engaged in the environmental surveys mentioned above ${ }^{4}$ and by specialists within the company. The amended list was then used as a coding guide and the coding was done blindly without knowledge of case-control status.

Information on smoking habits was not available for individual workers in this study.

\section{ANALYSIS}

Relative risks (RR) and confidence intervals $(\mathrm{CI})$ were computed using the method of conditional logistic regression for matched case-control sets with a variable matching ratio. ${ }^{5}$ Confidence intervals were not estimated when the number of exposed cases or controls was zero.

\section{Results}

Table 2 shows the numbers of cases and controls exposed to each of the fibre types by process where relevant, together with RR and $95 \%$ CI. RR for each fibre type are calculated for those who ever worked with it compared with those who never did. Some of the workers had more than one job and so the numbers in table 2 add up to more than the totals of cases and controls in table 1 . The categories in table 2 correspond to those described in the Methods section, together with some combinations. As may be seen there is a range of values for the RR from 0 for "superfine, flame attenuation" to $2 \cdot 0$ for "superfine, TEL process"- but these are based on only five and nine workers respectively. No RR are statistically significant either in excess or deficit of unity and some have wide confidence intervals. The "unknown" fibre type category, the largest in terms of numbers of workers, includes mainly jobs in maintenance and others not directly engaged with fibre production and is therefore not associated with any particular fibre type. By contrast, the categories of known fibre type are largely in the production and secondary process areas.

Grouping together all processes containing fibres in the respirable range, corresponding to the categories superfine and glass wool, gives a RR of 1.2 with a $95 \%$ $\mathrm{CI}$ of $0 \cdot 7-2 \cdot 0$. Combining the two superfine categories gives a RR of $1 \cdot 3(95 \% \mathrm{CI} 0 \cdot 3-5 \cdot 8)$. For the three glass wool categories together the RR is $1 \cdot 1(95 \% \mathrm{CI} 0.7-$ 1.9). Within glass wool the RR associated with the Owens process $(1.4)$ is higher than for TEL $(0.9)$, although the nominal fibre diameter was lower for the TEL process. Staple products, continuous filament, and air filter processes are not expected to generate respirable fibres and grouped together give a $R$ R of 1.2 with a $95 \% \mathrm{CI}$ of $0 \cdot 7-2 \cdot 3$. The RR for those potentially exposed to asbestos is $1 \cdot 5(95 \% \mathrm{CI} 0 \cdot 8-2 \cdot 5)$.

Logistic regression models were fitted, including terms for potential exposure to asbestos and unknown fibre types in addition to various categories of respirable fibres. In the first model the RR for the category superfine and glass wool together remained at 1.2 $(95 \%$ CI $0 \cdot 7-2 \cdot 0)$. In the second model superfine fibre and glass wool were included as separate terms, resulting in RR of $1 \cdot 1(95 \% \mathrm{CI} 0 \cdot 2-5 \cdot 2)$ and $1 \cdot 1(95 \%$ CI $0.6-1.9)$ respectively. The $R R$ for potential

Table 2 Numbers of cases and controls who ever worked with different types of fibre with relative risks (RR) and $95 \%$ confidence intervals

\begin{tabular}{|c|c|c|c|c|}
\hline \multirow[b]{2}{*}{ Fibre type } & \multicolumn{2}{|c|}{ No of workers } & \multirow[b]{2}{*}{$R R$} & \multirow[b]{2}{*}{$95 \% \mathrm{Cl}$} \\
\hline & Cases & Controls & & \\
\hline $\begin{array}{l}\text { Superfine, } \\
\text { flame attenuation } \\
\text { Superfine, TEL process } \\
\text { Superfine, combined } \\
\text { Wool, Owens process } \\
\text { Wool, TEL process } \\
\text { Wool, unspecified process } \\
\text { Wool, combined } \\
\text { Superfine and wool } \\
\text { Staple fibre or tissue } \\
\text { Air filter } \\
\text { Continuous filament } \\
\text { Unknown }\end{array}$ & $\begin{array}{r}0 \\
2 \\
2 \\
17 \\
20 \\
8 \\
31 \\
33 \\
11 \\
2 \\
1 \\
46\end{array}$ & $\begin{array}{r}5 \\
7 \\
12 \\
98 \\
162 \\
41 \\
218 \\
222 \\
59 \\
14 \\
17 \\
317\end{array}$ & $\begin{array}{l}0 \\
2.0 \\
1 \cdot 3 \\
1.4 \\
0.9 \\
1 \cdot 5 \\
1 \cdot 1 \\
1.2 \\
1.4 \\
0.9 \\
0.4 \\
0.9\end{array}$ & $\begin{array}{l}\overline{0.4-9.7} \\
0.3-5 \cdot 8 \\
0.7-2.5 \\
0.5-1 \cdot 6 \\
0.7-3.5 \\
0.7-1 \cdot 9 \\
0.7-2 \cdot 0 \\
0.7-2 \cdot 8 \\
0.2-4.0 \\
0.1-3.2 \\
0.5-1.6\end{array}$ \\
\hline Potential asbestos exposure & 24 & 130 & $1 \cdot 5$ & $0.8-2 \cdot 5$ \\
\hline
\end{tabular}


Table 3 Numbers of cases and controls employed in combined occupational categories with relative risks $(R R)$ and $95 \%$ confidence intervals

\begin{tabular}{|c|c|c|c|c|c|}
\hline \multirow[b]{2}{*}{ Occupational category } & \multirow{2}{*}{$\begin{array}{l}\text { Respirable* fibre } \\
\text { levels }(f / m l)\end{array}$} & \multicolumn{2}{|c|}{ No employed } & \multirow[b]{2}{*}{$R R$} & \multirow[b]{2}{*}{$95 \% C$} \\
\hline & & Cases & Controls & & \\
\hline \multicolumn{6}{|c|}{ (a) According to whether the workers had ever been employed in an occupational category } \\
\hline Secondary processes & 0.16 & 15 & 98 & $1 \cdot 2$ & $0 \cdot 7-2 \cdot 3$ \\
\hline Warehouses & 0.11 & 8 & 49 & $1 \cdot 2$ & $0 \cdot 5-2 \cdot 6$ \\
\hline Production & 0.05 & 19 & 137 & 1.0 & $0.6-1.8$ \\
\hline General works & 0.04 & 19 & 90 & $1 \cdot 5$ & $0 \cdot 8-2 \cdot 8$ \\
\hline Maintenance & 0.02 & 28 & 151 & $1 \cdot 5$ & $0 \cdot 9-2 \cdot 5$ \\
\hline Research and development & - & 6 & 45 & 0.9 & $0.4-2 \cdot 3$ \\
\hline Preproduction & 0.01 & 1 & 12 & 0.7 & $0 \cdot 1-5 \cdot 1$ \\
\hline Unknown & - & 14 & 85 & $1 \cdot 2$ & $0 \cdot 6-2 \cdot 3$ \\
\hline \multicolumn{6}{|c|}{ (b) According to the combined occupational category worked in with the highest exposure to respirable fibres } \\
\hline Secondary processes & $0 \cdot 16$ & 15 & 98 & $1 \cdot 2$ & $0 \cdot 7-2 \cdot 3$ \\
\hline Warehouses & $0 \cdot 11$ & 3 & 40 & $0 \cdot 5$ & $0 \cdot 1-1 \cdot 6$ \\
\hline Production & 0.05 & 15 & 106 & $1 \cdot 0$ & $0.5-1.9$ \\
\hline Secondary processes (less dusty) & 0.02 & 2 & 22 & 0.6 & $0 \cdot 1-2 \cdot 8$ \\
\hline Maintenance & 0.02 & 16 & 105 & $1 \cdot 1$ & $0 \cdot 6-2 \cdot 0$ \\
\hline Research and development & - & 1 & 15 & 0.5 & $0.1-3 \cdot 6$ \\
\hline Preproduction & 0.01 & 0 & 2 & 0 & -- \\
\hline Unknown & - & 5 & 51 & 0.6 & $0 \cdot 2-1 \cdot 7$ \\
\hline
\end{tabular}

*Fibre concentrations from environmental survey during $1977 .^{4}$

Measurements were not available for the research and development or unknown occupational categories.

exposure to asbestos remained at about 1.5 in both models and that for exposure to unknown fibre type was unchanged at $0 \cdot 9$.

Table 3 presents the results according to broad occupational categories in two different ways. Firstly, in the same manner as for fibre type in table 2 , comparing those workers ever versus never employed in each particular category and, secondly, as in the cohort analysis, assigning an individual to the highest exposure category (in terms of mean respirable fibre levels during 1977) ever worked in. The highest relative risks in table 3(a) are for the general works and maintenance categories (RRs 1.5). In table 3(b) the categories with higher estimated exposure to respirable fibres - that is, secondary processes, warehouses, and production -have RR of $1 \cdot 2,0 \cdot 5$, and $1 \cdot 0$ respectively. In general the results in table 3(b) accord well with those given for the full cohort analysis (see ref 1 , table 6). The only exception is general works, with a RR of 1.8 in the present analysis, which comprises such jobs as storemen, cleaners, yard labourers, and despatch (all considered possibly exposed) and locomotive drivers and weighbridgemen (considered non-exposed). In the cohort analysis for the general works category, which included more job titles than the present analysis, the lung cancer SMR was 104 compared with 110 for the entire exposed cohort using local expected numbers of deaths. None of the RRs in either section of table 3 is raised at a statistically significant level.

Table 4 gives results for the detailed job categories within broader categories. Many of the relative risks are based on small numbers but some are raised at a statistically significant level. For example, workers with granulating or blowing wool have a RR of 16.0 although only three workers were involved. Electrical maintenance workers show a raised RR of $3.4(95 \%$ CI 1.3-8.5) and boilermen of 5.0 (95\% CI 1.8-13.8). The other detailed occupational category with a significantly raised $R R$ is a poorly specified remainder category in warehouses. These raised RR are those occurring among many comparisons carried out, some of which must be expected by chance to result in high levels. Among the jobs with potential exposure to asbestos, in addition to electrical maintenance workers, mechanical maintenance workers show a raised relative risk $(R R=1.8)$ but not plumbers $(R R=0.9)$ or tank area workers $(R R=1 \cdot 1)$.

The roles of duration of exposure and interval since first exposure were examined after subdivision into ten year intervals $(0-9,10-19, \geqslant 20$ years $)$ for the exposure and job categories with sufficient numbers, but no statistically significant trends were observed. For those exposed to glass wool or superfine fibres, the pattern of $R R$ is irregular for analyses by either duration of exposure (RRs $1 \cdot 2,1 \cdot 8,0 \cdot 9$, respectively) or period since first exposure (RRs $0.6,2.0,1 \cdot 1$, respectively, with the second figure statistically significant and based on 17 exposed cases).

\section{Discussion}

This case-control study was set up with the specific aim of analysing relations between exposure to different 
Table 4 Numbers of cases and controls employed in different jobs by occupational category with relative risks (RR) and $95 \%$ confidence intervals

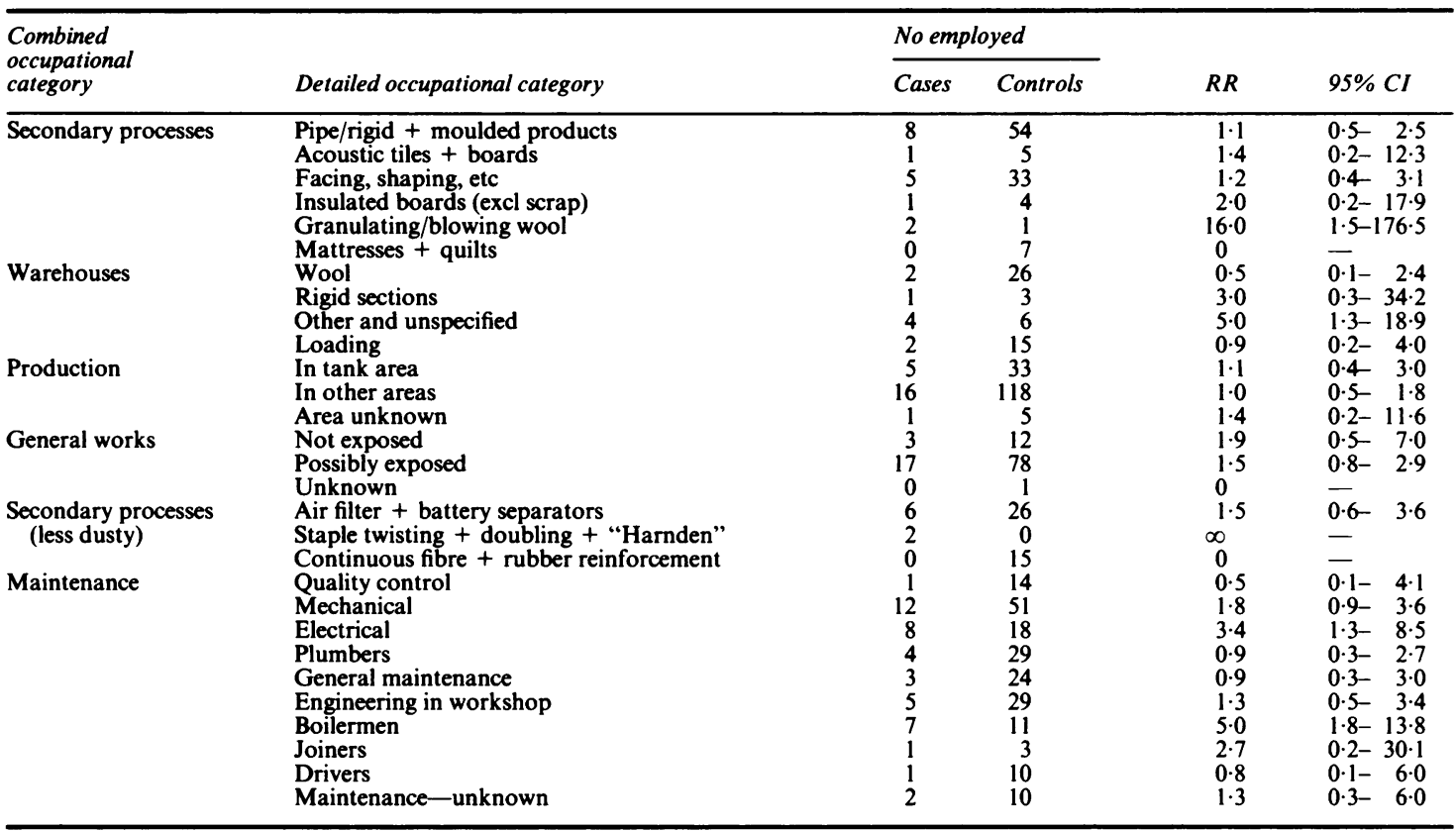

Preproduction and research and development could not be subdivided as more detailed occupational categories were not available.

types of glass fibre or to specific jobs and subsequent development of lung cancer. We have not found any consistent suggestion that any type of fibre, or grouping of fibres, or job category is associated with a pronounced increase in relative risk.

The possibility of respirable fibre generation increases with decreasing nominal fibre diameter. ${ }^{3}$ Thus more airborne respirable fibres would be expected from both superfine and wool than staple fibres and more from the TEL process than the Owens. In neither of these comparisons, however, is the former lung cancer RR higher than the latter.

Two small groups of individuals were identified who worked with superfine fibres, one with a raised relative risk based on two cases and the other with a deficit. The relative risk in the two groups combined is 1.3 reducing to $1 \cdot 1$ after controlling for potential exposure to asbestos and glass wool, and both with wide confidence intervals; thus little interpretation may be placed on these results. The figures are, however, comparable with the relative risk of respiratory cancer reported by Enterline et al in a study of glass fibre workers in the United States ever exposed to small diameter (less than 1.5 microns) fibres $(S M R=124)$ compared with those never exposed (SMR $=104) .{ }^{6}$

Changes in production methods such as the use of oil as a dust suppressant, improvements in ventilation, and increases in rates of output have all influenced levels of fibre exposure since the start of production. According to the company levels of airborne fibre were higher in the past, although probably not much more than an order of magnitude higher than recent measurements. Such respirable fibre levels would have been unlikely to result in detectable risks of lung cancer in a workforce of similar size exposed to asbestos.' Although workers producing or handling superfine fibres were probably exposed to higher levels of airborne fibres, this subgroup was small.

A relative risk of 1.5 , not statistically significant, for workers with potential asbestos exposure was found. When potential asbestos exposure was fitted simultaneously in models with respirable glass fibre, production process, and other variables it did not modify their relative risk estimates. Potential exposure to asbestos does not appear, therefore, to act as a confounder in this study with respect to exposure to glass fibre.

In conclusion, this study has not suggested a differential risk of developing lung cancer among workers exposed to finer diameter glass fibres compared with other workers. The exposure levels, however, were relatively low and the number of cases, in particular working with superfine fibres, presently available for study are small. 
We are grateful to the company for their cooperation in making the study possible, to $\mathrm{Mr} \mathrm{J}$ Cherrie of the Institute of Occupational Medicine, Edinburgh, for valuable advice, and to Mrs Brigid Howells who typed the manuscript.

Dr C Magnani carried out this work during the tenure of a research training fellowship awarded by the International Agency for Research on Cancer and Dr A C Fletcher was financially supported by the Health and Safety Executive.

\section{References}

1 Gardner MJ, Winter PD, Pannett B, Simpson MJC, Hamilton C, Acheson ED. Mortality study of workers in the man-made mineral fiber production industry in the United Kingdom.
Scand J Work Environ Health 1986;12(suppl 1):85-93.

2 Simonato L, Fletcher AC, Cherrie J, et al. The man-made mineral fiber European historical cohort study: extension of the followup. Scand J Work Environ Health 1986;12(suppl 1):34-47.

3 Cherrie J, Dodgson J. Past exposures to airborne fibers and other potential risk factors in the European man-made mineral fiber production industry. Scand $J$ Work Environ Health 1986;12(suppl 1):26-33.

4 Cherrie J, Dodgson J, Groat S, MacLaren W. Environmental surveys in the European man-made mineral fiber production industry. Scand J Work Environ Health 1986;12(suppl 1): 18-25.

5 Breslow NE, Day NE. Statistical methods in cancer research. Vol 1. The analysis of case control studies. Lyon: International Agency for Research on Cancer, 1980. (IARC sci publ No 32.)

6 Enterline PE, Marsh GM, Henderson V, Callahan C. Mortality update of a cohort of US man-made mineral fibre workers. Ann Occup Hyg 1987;31:625-56.

7 Doll R, Peto J. Asbestos: effects on health of exposure to asbestos. London: HMSO, 1985. 